\title{
Obstetric complications and adverse pregnancy outcomes among elderly primigravidae of age 35 years and above in Oman
}

\author{
Amira Al Ghailani ${ }^{1}$, Vaidyanathan Gowri ${ }^{2 *}$, Fatma Ali Said Al Hoqani ${ }^{1}$, Aisha Khamis Mohammed Al Belushi ${ }^{1}$ and M Mazharul Islam ${ }^{3}$ \\ ${ }^{1}$ Oman Medical Specialty Board, Oman \\ ${ }^{2}$ College of Medicine, Sultan Qaboos University, Muscat, Oman \\ ${ }^{3}$ College of Science, Sultan Qaboos University, Oman
}

\begin{abstract}
Objective: Worldwide it is becoming common to conceive at or beyond 35 years. In Oman, the age at marriage is increasing and more women are postponing childbearing. The tendency of delayed marriage and conception has effect on the mother and foetus. The objectives of this study were to review the obstetric complications and adverse pregnancy outcomes among elderly primigravidae of age 35 years and above compared to the younger primigravidae mothers of age 21-34 years in Oman.

Materials and method: The study was carried out at department of Gynecology and Obstetrics, Sultan Qaboos University Hospital (SQUH), Muscat, Oman, during the period between 2010 and 2016. The data for the study was extracted from the predesigned and approved data collection forms of the admissions and discharge registers of the obstetrics and gynecology ward of SQUH. Primigravidae at or older than 35 years at the time of delivery were classified as elderly primigravidae and those who are aged between 21 to 34 year were the control group. Maternal complications in pregnancy like gestational diabetes, hypertension, mode of delivery, neonatal outcome of all these women were collected from the hospital information records and delivery ward registry.
\end{abstract}

Results: There was a significant increase in the rate pre-eclampsia up to $19.2 \%$ compared to the control group of $4.1 \%$ and cesarean section rate up to $38.4 \%$ compared to control group of $21.9 \%$. There was no significant increase in other complications.

Conclusion: Maternal age at the first pregnancy influences pregnancy and neonatal outcome. Hence elderly primigravida women should be considered as high risk and followed up accordingly.

\section{Introduction}

Over the last four decades, many remarkable changes in the demographics of childbearing have been noticed in both developed and many developing countries [1-3]. Those changes include rising trends in age at first marriage, postponing childbearing until later reproductive years, and increasing proportion of mothers at advanced ages of as well as increasing proportion of primigravidae at advanced age in particular [4-7]. In the United States, for example, the percentage of first births for women $35-39$ years of age increased by $24 \%$ and that for women $40-44$ years of age increased by $35 \%$ between 2000 and 2012 [4,8].

The trend toward delaying pregnancy is mainly due to social, economic and cultural changes, but also to a better control of preexisting chronic disease, advances in assisted reproduction technologies and the availability of safe, effective contraception $[9,10]$. As educational, employment and career opportunities opened for women, they could choose between motherhood and other activities, which have fundamentally altered the temporal pattern of reproductive behavior $[11,12]$.

First-time mothers over 35 years are often called as "elderly primigravidae" and considered as "at risk," which is an issue of concern to the health professionals, women and their families [13-15]. However, whilst there are numerous studies in this area, with the majority of studies suggesting that increased maternal age ( 35 years of age or older) is associated with an increased risk of maternal morbidity, obstetric complications, and adverse pregnancy outcomes, some studies have demonstrated inconsistent conclusions about both the specific outcomes adversely affected by maternal age and the strength of the association [16,17]. These conflicting findings may be attributed to a number of methodological differences and limitations of the data. In addition, some studies have also demonstrated many positive aspects related to childbearing at a later age, such as better family functioning, higher family stability and a more stable economic position of parents $[18,20]$. This might be due to the fact that the contemporary older mothers tend to be well educated, of higher socio-economic status and of lower parity than older mothers from the recent past [21,22].

Like most western society, Oman, an oil rich Arabian Gulf Country, is passing through a rapid demographic transition [23]. In Oman age

${ }^{\star}$ Correspondence to: Vaidyanathan Gowri, Associate professor, College of Medicine and Health sciences Sultan Qaboos University, Muscat, Oman, Postal code 123, E-mail: gowrie61@hotmail.com; gowri@squ.edu.om

Key words: elderly primigravida, advanced maternal age, caesarean section, pregnancy outcome

Received: June 20, 2019; Accepted: June 27, 2019; Published: June 29, 2019 
at marriage is increasing [24] and the proportion of births occurring to women aged 35-49 years has increased $25 \%$ between 1988 and 2008 [25]. The important characteristics of the age pattern of recent fertility in Oman is that it is broad and flat topped, indicating a continuation of fertility at a higher rate until ages 35-39 [25]. The desire to have larger families, which is widely prevalent in Oman and in other Middle East countries, also implies that some of our patients in Oman voluntarily continue childbearing beyond 35 years. This changing reproductive behavior might have relation with the increasing trends in premature birth and low birth weight [26]. However, existing information about advanced maternal age, specifically regarding elderly primiparity at the ages $\geq 35$ years is limited.

Although, there are numerous studies on advanced maternal age and its relation with maternal morbidity, obstetric complications, and adverse pregnancy outcomes, research on elderly primigravidae is limited, and in research this group is often entrenched within a larger population, which is primarily multipara $[27,28]$. As the number of elderly primigravidae is growing and expected to rise further, it is necessary to determine whether they constitute a specific risk group requiring a unique clinical approach. Hence the purpose of this study is to review the obstetric complications and adverse pregnancy outcomes in Omani elderly primigravidae women. It is designed to compare pregnancy and birth outcomes of elderly primigravidae mothers with younger primigravidae aged 20-34 years. The research Question was that, does advanced maternal age in pregnancy carries more antepartum, intrapartum, postpartum and neonatal complications as compared to pregnancy among younger age. Our results may contribute to understanding of the risks associated with advanced maternal age. Results, outcome and findings may be useful in providing guidance to health care professionals and service providers in Oman.

\section{Methods and materials}

This study is based on a case-control study design. The elderly primigravidae mothers were considered as case, while the primigravida mothers of age 20-34 years of age were considered as control group. The study was carried out at the department of Gynecology and Obstetrics, Sultan Taboos University Hospital (SQUH), Muscat, Oman, during the period between 2010 and 2016. SQUH is a governmental educational medical institution for undergraduate and postgraduate medical training and research. It provides both secondary and tertiary medical care to general population. Patients from all over Oman from any socioeconomic background have free access to health care service at SQUH.

The data for the study was extracted from the predesigned and approved data collection forms of the admissions and discharge registers of the obstetric and gynecology ward of SQUH. These standardized delivery logs contain selected vital information about maternal demographic, and maternal complications in pregnancy like gestational diabetes, hypertension, mode of delivery, neonatal outcome of all women admitted in the hospital for delivery. Nurses or midwives fill these records upon admission and immediately after delivery. All these records are routinely kept in the hospital as hard copy. For the purpose of this study, the data were extracted using the inclusion criteria: Omanis, not known to have any medical disease, spontaneous conception and a singleton pregnancy. Those who were non-Omanis, history of any medical disease and history of previous miscarriage, multiple pregnancies and ovulations induced pregnancies were all excluded. During our data collection period, 73 elderly primigravidae mothers were selected. An equal number of 73 mothers of age between
20-34 years were selected as control group using the same inclusion criteria.

The data entry and analysis were done using SPSS software. Statistical analysis was performed to evaluate the association between advanced maternal age at first pregnancy ( $\geq 35$ years) and specific obstetric problems and outcomes. Control aged group mothers of age 20-34 years at the time of delivery constituted the reference category.

Univariate analyses included $t$ test for continuous variables and Chi-square test for categorical variables or Fisher's exact test for small cell sizes. Missing data were not included in the analyses. A P value of $<0.05$ was considered significant. Univariate and multivariable logistic regression model were employed to estimate the unadjusted and adjusted risk of specific obstetric complications and neonatal outcomes of the elderly primigravidae with reference to pregnancy to mothers aged 20-34 years. The risk was measured by the odds ratio.

\section{Results}

The study started with total of 230 primigravidae, all delivered in SQUH. However, 83 cases were excluded due to having history of medical diseases, previous miscarriage or ectopic pregnancies or a pregnancy that happened after assisted reproductive technologies. Of the remaining 146 cases, 73 cases were elderly primigravidae (the case) and the rest 73 cases were the primigravidae mothers of age 21-34 years (the control). The mean age of women in the cases group was observed to be $36.6 \pm 1.6(\mathrm{SD})$ years with mean gestational age at delivery $38.3 \pm$ $2.5(\mathrm{SD})$ years. The mean age of women in controls group was observed to be $26.8 \pm 3.44(\mathrm{SD})$ years with mean gestational age at delivery $38.2 \pm$ 1.8 (SD) years. There was no significant difference in mean gestational age of the two groups of mothers.

Table 1 presents the prevalence of specific obstetric complications and neonatal outcomes among elderly primigravidae mothers and the primigravidae mothers of age 21-34 years as well as the risk ratio of specific obstetric complications and neonatal outcomes of elderly primigravidae mothers with reference to control group mothers. The results indicate significantly higher risk of preeclampsia, caesarean section delivery and perinatal trauma among the elderly primigravidae mothers than those of control group mothers of age 21-34 years. For example, the prevalence of pre-eclampsia was $19.2 \%$ among the elderly primigravidae group compared to $4.1 \%$ among the control group. The elderly primigravidae group had 6 times higher risk of pre-eclampsia than their younger peers of age $20-34$ years $(\mathrm{OR}=6.03$; 95\% CI: 1.66 21.86). The elderly primigravedae mothers had 2.2 times higher risk of caesarean section delivery than the control group mothers $(\mathrm{OR}=2.21$; 95\% CI:1.07 - 4.59). The rate of caesarean section delivery was observed to be $38.4 \%$ among the elderly primigravidae as oppose to $21.9 \%$ among the control group. Perinatal trauma also increased significantly among elderly primi $(9.6 \%)$ than the control group (5.5\%). Elderly primi had 2.1 times higher risk of perinatal trauma than the control group mothers (OR=2.10; 95\% CI:1.02 - 3.79).

The above mentioned significant higher risk of pre-eclamsia, caesarean section delivery and perinatal trauma among the elderly primigravidae mothers than the control group mothers, however, obtained through univariate analysis, providing unadjusted effect of maternal age. To obtain adjusted effect of maternal age on obstetric complications and neonatal outcomes, multiple logistic regression analysis were done considering each of the obstetric complications and neonatal outcomes as outcome variable and maternal age as predictor after controlling the potential effect of other obstetric complications and neonatal outcomes. The results are presented in Table 2. Multivariate 
Table 1. Obstetric complications and neonatal outcomes by maternal age

\begin{tabular}{|c|c|c|c|c|}
\hline \multirow{2}{*}{$\begin{array}{l}\text { Obstetric complications, and } \\
\text { neonatal outcomes }\end{array}$} & \multicolumn{2}{|c|}{ Maternal age } & \multirow{2}{*}{$\begin{array}{l}\text { Unadjusted } \\
\text { Odds ratio } \\
(95 \% \mathrm{CI})\end{array}$} & \multirow[b]{2}{*}{ P value } \\
\hline & $\begin{array}{c}\text { 21-34 years } \\
(\mathrm{n}=73)\end{array}$ & $\begin{array}{c}\geq 35 \text { years } \\
(n=73)\end{array}$ & & \\
\hline Anemia & 13.7 & 11.0 & $0.78(0.28-2.09)$ & 0.615 \\
\hline Gestational Diabetes & 19.2 & 24.7 & $1.37(0.63-3.04)$ & 0.424 \\
\hline Mean gestational age (week) \pm SD & $38.3 \pm 1.8$ & $38.2 \pm 2.5$ & & 0.852 \\
\hline Preeclampsia & 4.1 & 19.2 & $6.03(1.66-21.86)$ & 0.003 \\
\hline Preterm labor & 11.0 & 9.6 & $0.86(0.29-2.51)$ & 0.785 \\
\hline IUGR & 11.0 & 6.8 & $0.60(0.186-1.92)$ & 0.383 \\
\hline Cesarean section delivery & 21.9 & 38.4 & $2.21(1.07-4.59)$ & 0.032 \\
\hline Perinatal trauma & 5.5 & 9.6 & $2.10(1.02-3.79)$ & 0.048 \\
\hline Postpartum hemorrhage & 5.5 & 6.8 & $1.26(0.32-4.92)$ & 0.731 \\
\hline Low birth weight (<2500 gm) & 17.8 & 13.7 & $0.73(0.29-1.79)$ & 0.496 \\
\hline Premature birth (<37 week) & 15.1 & 16.4 & $1.10(0.45-2.70)$ & 0.820 \\
\hline NICU admission & 8.2 & 11.0 & $1.39(0.45-4.17)$ & 0.574 \\
\hline
\end{tabular}

IUGR = Intrauterine growth retardation

$\mathrm{NICU}=$ Neonatal Intensive Care Unit

Table 2. Results of multiple logistic regression analysis showing the adjusted risk of Obstetric complications for elderly primigravidae

\begin{tabular}{|c|c|c|c|}
\hline Obstetric complications & Adjusted odds ratios $^{\mathbf{a}}$ & 95\% CI & P-value \\
\hline Preeclampsia & 12.18 & $2.43-24.78$ & 0.004 \\
\hline Cesarean section delivery & 2.25 & $1.05-4.83$ & 0.038 \\
\hline Perineal trauma & 2.53 & $0.56-11.61$ \\
\hline
\end{tabular}

aAdjusted odds ratios were obtained after controlling the potential confounding effects of other obstetric complications, such as gestational age, anemia, gestational diabetes, preterm labour, etc.

analysis identified elderly primigravidae as the significant predictor for pre-eclamsia and caesarean section. Although, perinatal trauma showed significant higher risk for elderly primigravidae mothers in univariate logistic regression analysis, it becomes insignificant in multivariate analysis. Multivariate analysis showed elevated higher risk of pre-eclampsia and caesarean section delivery among elderly primigravidae mothers than control group mothers, indicating elderly primigravidae as independent significant predictor of these two obstetric complications.

Our analysis showed higher prevalence of gestational diabetes, postpartum hemorrhage, premature birth and NICU admission among the elderly primigravidae mothers than their peers of age 21-34 aged mothers. However, the differences were not statistically significant. The prevalence of gestational diabetes was found to be higher among elderly primigravidae than the control group ( $24.7 \%$ vs $19.2 \%)$, and the risk of gestational diabetes was 1.37 times higher among the elderly primigravidae group than the control group. However, the effect was not statistically significant (OR=1.37; 95\% CI: 0.63 - 3.04).

On the other hand, elderly primigravidae mothers were found to have lower risk of certain obstetric complications and neonatal outcomes, such as anemia, preterm labor and low birth weight, than the control group mothers. However, the differences were not statistically significant. For example, anemia was less prevalent among elderly primigravidae compared to younger primi of age $20-34$ years $(11.0 \%$ vs $13.7 \%)$.

\section{Discussion}

The main objective of this study was to investigate if elderly primigravidae is a risk factor for obstetric complications and adverse outcomes pregnancy outcomes using a hospital-based case-control type study design in Oman. In contrast to most other studies relating to advanced maternal ages irrespective of parity, this study population included only elderly primigravidae of age $\geq 35$ years. This would help understand the extend of risk of obstetric complications, and neonatal outcomes among the first-time mothers at an advanced age of 35 years or more.

The main findings of the study indicated that elderly primigravidae bears significantly higher risk of pre-eclampsia and caesarean section delivery compared to younger mothers of age 21-34 years. A recent population based study in Oman also reported higher risk of preeclampsia and caesarean section delivery among elderly mothers of age 35 years or more irrespective of their gravidae [25]. Our finding of higher pre-eclampsia among elderly primigravidae is consistent with finding of Ben-David et al reporting higher risk of pre-eclampsia among first time mothers of very advanced maternal age $\geq 40$ years in Israel [29].

We also found an incremental and highly significant increase in the rate of Caesarean delivery in primigravidae elderly women aged 35 years and more when compared to women aged 21-34 years. This is in line with the findings of other researchers. For example, Bell et al. [30] who reported caesarean rates in the range of $25-35 \%$ for women aged $\geq 35$ years and approximately $40 \%$ for women aged $>40$ years compared with estimates of $14-20 \%$ for women aged $<35$ years. In our study, increased rate of cesarean section up to $38.4 \%$ compared to control group of $21.9 \%$ with $\mathrm{OR}=2.25,95 \% \mathrm{CI}$ : $1.05-4.83$, P-value of 0.038 . This finding has implications for maternity service providers, particularly as trends of advanced maternal age continue.

Various reasons have been offered to explain increased risk of caesarean delivery among advanced-age mothers, including increasing obstetric complications with aging, non-reassuring fetal status in older age, increasing obesity with aging, increasing risk of abnormalities in the course of labour, malpresentation, multiple gestations, placenta praevia, macrosomia, arrest of descent, prior uterine surgeries, arrest of dilatation ,induction of labour, repeat caesarean delivery, and caesarean delivery on maternal request [13,31-33]. Insufficient myometrial efficiency with aging may also be a possible reason for increased caesarean delivery 
among advanced-age mothers [34]. Advanced maternal age has also been observed that may be alone a factor influencing both mother and physician's decision to have caesarean delivery [35].

Advanced maternal age has been found to be associated with a range of adverse pregnancy outcomes [15,36-38]. Like many other previous studies, our analysis showed higher prevalence of gestational diabetes, postpartum hemorrhage, premature birth and NICU admission among the elderly primigravidae mothers than their younger primigravidae of age 21-34 aged mothers. However, the differences were not statistically significant. Unlike the findings of most previous study, our analysis showed lower risk of certain obstetric complications and neonatal outcomes, such as anemia, preterm labor and low birth weight, among elderly primigravidae than the control group mothers. However, the differences were not statistically significant. The non-significant differences in above mentioned cases might have some relation with the small sample sizes of our study groups and the changing demographic and socioeconomic characteristics of contemporary elderly primigravidae. The small sample size of the study subjects may limit the ability to test the statistical significance, because it is likely to provide wider confidence intervals for some study variables suggesting lack of power. On the other hand, the contemporary elderly mothers are likely to be well educated [21], and of higher socio-economic status than older mothers from the recent past [39]. It has been suggested that social advantage may ameliorate some of the adverse effect of advanced maternal age on perinatal Outcome [40]. In recent years, older women who become pregnant are more often primiparous and of better socio-economic status while in the past they were more often multiparous and of low socio-economic status $[40,41]$.

The present study has several limitations. Firstly, this is a retrospective study based on medical records. This prevented us to include many important variable, such as maternal health and nutrition level, their life style, level of education and socio-economic status. Secondly, the study population included only women who gave birth at SQU hospital, and the results may not be generalized. Thirdly, as mentioned above, the small sample size of the study subjects limits the ability to test the statistical significance.

\section{Conclusion}

In conclusion, this study focused on primiparae, distinguishing it from most other studies relating to advanced maternal age. Maternal age at the first pregnancy carries influences on the mother, pregnancy and neonatal outcome Hence elderly primigarvidae are considered as high risk pregnancy and they need special attention and care during pregnancy and child birth. By knowing and understanding the risk of complications, we expect to establish better standards in practice.

\section{References}

1. Frejka T, Jones GW, Sardon JP (2010) East Asian childbearing patterns and policy developments. Popul Dev Rev 36: 579-606.

2. Ngowa JDK, Ngassam AN, Dohbit JS, Nzedjom C, Kasia JM (2013) Pregnancy outcome at advanced maternal age in a group of African women in two teaching Hospitals in Yaounde, Cameroon. Pan Afr Med J 14: 134. [Crossref]

3. Rehman BU, Sirwal RK, Wani FA (2017) A comparative prospective study of maternofetal outcome in advanced and younger maternal age group in higher socioeconomic strata. Int J Reprod Contracept Obstet Gynecol 6: 1362-1367

4. Heffner LJ (2004) Advanced maternal age--how old is too old? N Engl J Med 351: 1927-1929. [Crossref]

5. Billari F, Kohler HP, Andersson G, Lundström H (2007) Approaching the limit: Longterm trends in late and very late fertility. Popul Develop Rev 33: 149-170.
6. Prioux F. Recent demographic developments in France: Fertiltiy at a more than 30 year high I.N.E.D. Population 2007/3 62: 417 - 456 Translated by Jonathan Mandelbaum

7. Mathews T, Hamilton B (2009) Delayed childbearing: More women are having their first child later in life.. USA: US Department of Health and Human Services, Centers for Disease Control and Prevention, National Center for Health Statistics. NCHS Data Brief 21: 1-8.

8. Mathews TJ, Hamilton BE (2014) First births to older women continue to rise. NCHS data brief, no 152. Hyattsville, MD: National Center for Health Statistics. NCHS Data Brief 152: 1-8.

9. Harker L, Thorpe K (1992) 'The last egg in the basket': Elderly primiparity-A review of the findings. Birth 19: 23-30. [Crossref]

10. Blickstein I (2000) Motherhood at or beyond the edge of reproductive age. Int J Fertil 48: 17-24. [Crossref]

11. Van de Kaa DJ (1987) Europe's second demographic transition. Popul Bul 42: 1-59. [Crossref]

12. Goldin C (2006) The quiet revolution that transformed women's employment education, and family. Am Econ Rev 96: 1-21.

13. Lean SC, Derricott H, Jones RL, Heazell AEP (2017) Advanced maternal age and adverse pregnancy Advanced maternal age and adverse pregnancy outcomes: A systematic review and meta-analysis A systematic review and meta-analysis. PLoS One 12: e0186287. [Crossref]

14. Kenny LC, Lavender T, McNamee R, O’Neill SM, Mills T, et al. (2013) Advanced maternal age and adverse pregnancy outcome: evidence from a large contemporary cohort. PLoS One 8: e56583. [Crossref]

15. Joseph KS, Allen AC, Dodds L, Turner LA, Scott H, et al. (2005) The perinatal effects of delayed childbearing. Obstet Gynecol 105: 1410-1418. [Crossref]

16. Berkowitz GS, Skovron ML, Lapinski RH, Berkowitz RL (1990) Delayed childbearing and the outcome of pregnancy. $N$ Engl J Med 322: 659-664. [Crossref]

17. Wang Y, Tanbo T, Abyholm T, Henriksen T (2011) The impact of advanced maternal age and parity on obstetric and perinatal outcomes in singleton gestations. Arch Gynecol Obstet 284: 31-37. [Crossref]

18. Hardy JB, Astone NM, Brooks-Gunn J, Shapiro S, Miller TL (1998) Like mother, like child: intergenerational patterns of age at first birth and associations with childhood and adolescent characteristics and adult outcomes in the second generation. Dev Psychol 34: 1220-1232. [Crossref]

19. Taniguchi H (1999) The timing of childbearing and women's wages. J Mar Fam 61 1008-1019.

20. Miller AR (2010) The effect of motherhood timing on career path. J Popul Econ 24 1071-1100.

21. Ales KL, Druzin ML, Santini DL (1990) Impact of advanced maternal age on the outcome of pregnancy. Surg Gynecol Obstet 171: 209-216. [Crossref]

22. Islam MM (2017) Rapid fertility decline in Oman: Understanding the role of proximate determinants. Middle East Fert Soc J 22: 275-284.

23. Islam MM, Dorvlo A S S, Al Qasmi AM (2011) Proximate determinants of declining fertility in Oman in the 1990s. Can Stud Popul 33-4: 133-152.

24. Islam MM, Bakheit CS (2015) Advanced maternal age and risks for adverse pregnancy outcomes: a population-based study in Oman. Health Care Women Int 36: 1081-1103. [Crossref]

25. Islam MM (2015) Increasing Incidence of Infants with Low Birth Weight in Oman Sultan Qaboos Univ Med J 15: 177-183. [Crossref]

26. Carolan MC, Davey MA, Biro M, Kealy M (2013) Very advanced maternal age and morbidity in Victoria, Australia: A population based study. BMC Pregnancy Childbirth 13: 80. [Crossref]

27. Le Ray C, Scherier S, Anselem O, Marszalek A, Tsatsaris V, et al. (2017) Association between oocyte donation and maternal and perinatal outcomes in women aged 43 years or older. Hum Reprod 27: 896-901. [Crossref]

28. Ben-David A, Glasser S, Schiff E, Zahav AS, Boyko V, et al. (2016) Pregnancy and Birth Outcomes Among Primiparae at Very Advanced Maternal Age: At What Price? Matern Child Health J 20: 833-842. [Crossref]

29. Bell JS, Campbell DM, Graham WJ, Penney GC, Ryan M, et al. (2001) Can obstetric complications explain the high levels of obstetric interventions and maternity service use among older women? BJOG 108: 910. [Crossref] 
30. Cleary-Goldman J, Malone FD, Vidaver J, Ball RH, Nyberg DA, et al. (2005) Faster Consortium. Impact of maternal age on obstetric outcome. Obstet Gynecol 105: 983990. [Crossref]

31. Ecker JL, Chen KT, Cohen AP, Riley LE, Lieberman ES (2001) Increased risk of cesarean delivery with advancing maternal age: indications and associated factors in nulliparous women. Am J Obstet Gynecol 185: 883-887. [Crossref]

32. Conde-Agudelo A, Belizan JM, Diaz-Rossello JL (2000) Epidemiology of fetal death in Latin America. Acta Obstet Gynecol Scand 79: 371-378. [Crossref]

33. Cohen W (2014) Does maternal age affect pregnancy outcome? BJOG 121: 252-254.

34. Bayrampour H, Heaman M (2010) Advanced maternal age and the risk of cesarean birth: a systematic review. Birth 37: 219-226. [Crossref]

35. Jolly M, Sebire N, Harris J, Robinson S, Regan L (2000) The risks associated with pregnancy in women aged 35 years or older. Hum Reprod 15: 2433-2437. [Crossref]
36. Aliyu MH, Salihu HM, Wilson RE, Alio AP, Kirby RS (2008) The risk of intrapartum stillbirth among smokers of advanced maternal age. Arch Gynecol Obstet 278: 39-45. [Crossref]

37. Hoffman MC, Jeffers S, Carter J, Duthely L, Cotter A, et al. (2007) Pregnancy at or beyond age 40 years is associated with an increased risk of fetal death and other adverse outcomes. Am J Obstet Gynecol 196: e11-e13. [Crossref]

38. Carolan M (2003) The graying of the obstetric population: implications for the older mother. J Obstet Gynecol Neonatal Nurs 32: 19-27. [Crossref]

39. Ales KL, Druzin ML, Santini DL (1990) Impact of advanced maternal age on the outcome of pregnancy. Surg Gynecol Obstet 171: 209-216. [Crossref]

40. Carolan M, Frankowska D (2011) Advanced maternal age and adverse perinatal outcome: a review of the evidence. Midwifery 27: 793-801. [Crossref]

41. Chan BC, Lao TT (2008) Effect of parity and advanced maternal age on obstetric outcome. Int J Gynaecol Obstet 102: 237-241. [Crossref]

Copyright: $\bigcirc 2019 \mathrm{Al}$ Ghailani A. This is an open-access article distributed under the terms of the Creative Commons Attribution License, which permits unrestricted use, distribution, and reproduction in any medium, provided the original author and source are credited. 